\title{
Breaking bad news to Togolese patients
}

To cite this article:

Kpanake, L., Sorum, P. C., \& Mullet, E. (2016). Breaking bad news to Togolese patients. Health Communication, 31, 1311-1317. 


\begin{abstract}
The aim of this study was to map Togolese people's positions regarding the breaking of bad news to elderly patients. Two hundred eleven participants who had in the past received bad medical news were presented with 72 vignettes depicting communication of bad news to elderly female patients and asked to indicate the acceptability of the physician's conduct in each case. The vignettes were all combinations of five factors: (a) the severity of the disease, (b) the patient's wishes about disclosure, (c) the level of social support during hospitalization, (d) the patient's psychological robustness, and (e) the physician's decision about how to communicate the bad news. Five qualitatively different positions were found. Two percent of the participants preferred that the physician always tell the full truth to both the patient and her relatives, $8 \%$ preferred that the truth be told depending on the physician's perception of the situation, $15 \%$ preferred that the physician tell the truth, but understood that in some cases, nondisclosure to the patient was not inappropriate, $33 \%$ preferred that the physician tell the full truth to the relatives but not as much information to the patient, and $42 \%$ preferred that the physician tell the full truth to the relatives only. These findings present a challenge to European physicians taking care of African patients living in Europe or working in African hospitals, and to African physicians trained in Europe and now working in their home countries. If these physicians respect the imperative of always telling the truth directly to their patients, their behavior may trigger anger and considerable misunderstanding among African patients and their families.
\end{abstract}




\section{INTRODUCTION}

Notifying patients that they have a poor prognosis is stressful, even for physicians who routinely deliver bad news. Most physicians admit that they are unsure of their ability to perform this task properly (Pauls \& Ackroyd-Stolarz, 2006; Sise, Sise, Sack, \& Goerhing, 2006). Yet patient-clinician communication has a major impact on (a) patients' psychological adjustment to illness (Shofield, Butow, Thompson, Tattersall, Beeney, \& Dunn, 2003); (b) their adherence to treatment (Watermeyer \& Penn, 2012); (c) the outcome of the treatment itself (Franks, Fiscella, Shields, Meldrum, Duberstein, Jerant, et al., 2005); (d) future patient-clinician relationships (Barnett, Fisher, Cooke, James, \& Dale, 2007); and (e) patients' complaints to the justice system (Levinson, Roter, Mullooly, Dull, \& Frankel, 1997). Guidelines on how to deliver bad news to adult patients, such as SPIKES and ABCDE (Kaplan, 2010; Fields \& Johnson, 2012), tell physicians to be sensitive to individual patients' preferences, capacities, and needs. According to Levinson, Lesser, and Epstein (2010), physicians should try to find out how patients prefer that bad news be delivered in order to tailor their communication styles to patients' needs.

Several studies have suggested considerable inter-individual variations in people's preferences. In a study in Japan, a diversity of positions was found regarding cancer patients' preferences for the disclosure of their prognosis. About $6 \%$ preferred not to be told anything if the news was bad; $48 \%$ preferred partial disclosure; $17 \%$ preferred full gradual disclosure; and $30 \%$ preferred full disclosure without delay (Miyata, Takahashi, Saito, Tachimori, \& Kai, 2005). Similarly, in a study in Turkey, $48 \%$ of people accompanying cancer patients preferred that the physician disclose a cancer diagnosis to the patient, 39\% preferred that the physician hide the diagnosis from the patient, and 13\% were uncertain (Öksüzoğlu, Abalı, Bakar, Yıldırım, \& Zengin, 2006). In a study in France, 193 adults rated the appropriateness of scenarios depicting 
circumstances of breaking bad news to elderly patients (Igier, Muñoz Sastre, Sorum, \& Mullet, 2015). Cluster analysis found four different positions: $28 \%$ of the participants preferred that the full truth be told to patients in all circumstances, $36 \%$ preferred the full truth to be told, but understood that the physician would inform the family first, $13 \%$ did not think that telling the full truth was good for any patient, and $23 \%$ preferred the full truth to be told in some cases and not in others, depending on the physician's perception of the situation.

Evidence also suggests considerable cross-cultural variations in people's views about communicating bad news. Whether to disclose bad news to a patient or not is rooted in the dominant values in each culture (Barclay, Blackhall, \& Tulsky, 2007; Blank, 2011; Wuensch et al., 2013). Preference for full disclosure found among Westerners is grounded on the ethical principle of autonomy (Beauchamp \& Childress, 2008), which arises from cultural values such as individual freedom and self-determination (Fox, 1990; Kleinman, 1999). These values are, however, not necessarily shared by other cultures of the world. Accordingly, while in European societies a majority of people expect physicians to disclose the news, either good or bad, directly to the patient (Hagerty et al. 2005; Igier et al., 2015), in Asian and Arab societies, in contrast, people expect physicians to inform the patient's family first, who then decides whether the patient should be informed or not (Silbermann \& Hassan, 2011; Wuensch et al., 2013).

Most African cultures do not promote individual autonomy, but instead consider the community--collective relatedness, interdependence, and communality - to be the essential source of meaning and the main frame of action for an individual (Brown, 2004; Asante \& Mazama, 2008; Hallen, 2009). For health communication, the family group, in particular, is primary (Beyene, 1992; Harris, Shao, \& Sugarman, 2003). Furthermore, African systems of thought are rich with supernatural forces that do not create boundaries between the material and 
the non-material spheres (Brown, 2004). One popular belief across the African continent is the active power of speaking: merely talking about a bad outcome may prompt its occurrence (Blier, 1996). This belief is so strong that, in some societies, simply talking about death in general is taboo (Beyene, 1992).

While substantial knowledge is now available on Western people's perspectives on breaking bad news, little attention has been paid to Africans' perspectives. This is unfortunate because, in a context of high mortality rates due to cancer, AIDS, malaria, and other diseases (United Nations, 2013), this knowledge would be very useful. The few studies conducted in Africa have, using qualitative approaches, attempted (a) to understand physicians' decisions concerning the disclosure of bad news to cancer patients and their families in Tanzania (Harris, Shao, \& Sugarman, 2003) and (b) to explore the information needs of patients with progressive life-threatening diseases and their family caregivers in South Africa and Uganda (Selman, et al. 2009). Findings from Tanzania suggest that physicians often withhold bad news from patients and justify this by invoking patients' cultural beliefs and the lack of available treatment. Furthermore, many of them advocated the use of a "roundabout" approach to disclosure, arguing that it was reflective of the local normal mode of discourse.

Owing to the absence of cross-cultural studies using comparable methodologies, whether and in what ways African people's perspectives regarding the breaking of bad news really differ from those found in Western societies is, however, still not completely clear. The present study, which was modelled after Igier et al. (2015), aimed at filling this gap. It examined the personal positions of African people in a way that allowed direct comparisons with findings from Western European samples.

Hypotheses 
First, we expected our participants — who, like people around the world, have been subject to a variety of personal experiences and cultural influences-to express the same diversity of preferences found in other cultures. We expected, therefore, to find groups of participants who think a) that the physician should always tell the full truth to both the patient and her relatives; b) that the physician should tell the bad news to the relatives but not to the patient; c) that the type of communication should depend on the patient's wishes, the patient's psychological condition, and other contextual elements; and d) that the physician should hide the truth from the patient. Second, owing to the dominant African cultural values of collective relatedness, interdependence, and communality, we expected a very different frequency of these preferences, i.e., that most of our participants would favor either telling the truth to the relatives, but not to the patients, or not telling the truth to neither the patients nor the relatives.

\section{METHOD}

\section{Participants}

The participants were unpaid volunteers recruited and tested by five trained research assistants who contacted a total of 800 people walking along the sidewalks of Lomé, the capital and largest city of Togo. The diversity of its population enabled the recruitment of participants with various demographic characteristics. In order to select participants able to understand fully

the issues involved in the study, the assistants asked these passers-by whether they had ever been told bad medical news by a physician. If they had, the assistants explained the study and invited them to participate. Of the 358 persons who had received bad medical news, 211 (103 female and 108 male) agreed to participate. Informed consent was obtained from all participants and full anonymity was provided. The main reasons for refusal to participate were lack of available time 
and interest. Participants' ages ranged from 18 to 63 years $(M=24, S D=9.50)$. Detailed demographic characteristics are shown in Table 1. The language used for this research was French, the official language of Togo.

\section{Material}

The material was adapted from Igier et al. (2015), using the same variables. It consisted of 72 cards containing a story of a few lines, a question, and a response scale. In the vignettes, all the patients were identified as females and were about 70 years of age; they were cognitively intact. The stories were designed according to a five within-subject orthogonal factor design:

1. The severity of the disease: a. severe but not lethal: the illness can be cured; b. severe, and lethal in one case out of three: a several-month period of hospitalization must be considered; or c. incurable, with a life expectancy of a few months: the patient must remain in the hospital.

2. The elderly patient's wishes regarding disclosure: a. insists on knowing the full truth; or b. wishes to know about her illness, but does not insist on knowing the full truth.

3. The level of social support during hospitalization: a. will have many visits from her relatives; or b. will be relatively alone.

4. The elderly patient's psychological robustness: a. psychologically robust; or b. psychologically frail.

5. The physician's decision about communicating bad news: a. hid the truth from the elderly patient and her relatives; $b$. hid the truth from the elderly patient but told the full truth to her relatives; c. told the full truth to both the elderly patient and her relatives.

The following is an example of a story: "Mrs. Afanou is 70 years old. She suffers from an extremely serious illness that is incurable given present knowledge. She will have to stay in the 
hospital. Her life expectancy is a few months. Mrs. Afanou is a person known to be psychologically robust. She is, however, isolated; her only family members live far away. She will hardly have any visitors. Mrs. Afanou wants to know what she is suffering from but does not insist on knowing the absolute truth. Dr. Amégan decided to hide the truth from Mrs. Afanou and from her family. He told them that the illness was severe but that her life was not in danger."

Under each story were a question and a response scale. The question was: "To what extent do you consider that the physician's behavior was, in this case, appropriate?" The response scale was an 11-point scale with a left-hand anchor of "Not at all" and a right-hand anchor of "Completely." The cards were arranged by chance and in a different order for each participant.

\section{Procedure}

The researchers found a quiet place to administer the experiment, at the time of the first encounter for $68 \%$ of the participants and on another day in the same week for the remaining $32 \%$. The site was either a vacant classroom in the local university or another place, depending on what was most convenient for the participant. Testing was strictly individual. The session had two phases. In the familiarization phase, the experimenter explained what was expected and presented each participant with 24 stories taken randomly from the complete set. The participant read each story out loud, was reminded by the experimenter of the items of information in the story, and then made an appropriateness rating by putting a mark on the response scale. After completing the 24 ratings, the participant was allowed to look back at his or her responses and to compare and change them. The purpose of the familiarization phase was to make the participant as familiar as possible with the test material and the task (Anderson, 2008). In the experimental phase, each participant gave ratings for the whole set of 72 stories, working at his or her own 
pace, but was not allowed to look back at and change previous responses. No participant withdrew from the study after starting it. The participants took 30-50 minutes to complete both phases. At the end of the session, the participants answered additional questions about their age, gender, educational level, and religion. The study was approved by the Institutional Review Board of the University of Quebec-Teluq.

\section{RESULTS}

For each of the 72 scenarios in the experimental phase, the response was converted to a numerical value ranging from 0 to 10; all subsequent analyses were based on these measures. Owing to the multiple comparisons, the significance threshold was set at .001 .

As expected, strong individual differences in responses were detected during preliminary data analysis. Cluster analysis was, therefore, performed using the K-means method advocated by Hofmans and Mullet (2013). As four clusters were expected, a four-cluster solution was first tested, and the clusters that were found were then tentatively interpreted. Thereafter, a threecluster and a five-cluster solution were tested as alternatives. The five-cluster solution was finally retained because it was the one that produced the most interpretable findings. Separate analyses of variance (ANOVAs) were conducted on the data of the four clusters with sufficient numbers of participants using a Severity x Wishes x Support x Psychological robustness x Physician's decision, $3 \times 2 \times 2 \times 2 \times 3$ design. Chi $^{2}$ tests were performed with the demographic characteristics as independent variables.

The distribution of participants in each of the five clusters is shown in Table 1. The main patterns of data that correspond to each cluster are shown in Figure 1. In each panel, judged appropriateness of the physicians' behavior is on the vertical axis. The three possible physician 
behaviors are on the horizontal axis. The two curves correspond to the two levels of the patients' psychological robustness. Finally, each panel corresponds to one cluster of participants. The effect of the level of social support during hospitalization, the effect of the severity of the disease, and the effect of the patients' wishes were not shown because their impact was generally weak. The detailed results of the corresponding ANOVAs are shown in Table 2.

For 3 participants (2\%), telling the full truth to both the patient and her relatives was the only appropriate decision $(M=8.95)$, and the corresponding cluster was called "Always tell the full truth". Hiding the truth from the patient $(\mathrm{M}=1.59)$ or not telling the full truth to anybody $(\mathrm{M}=0.93)$ was considered as clearly inappropriate, irrespective of the other circumstances (see Figure 1, left panel).

For 32 participants (15\%), telling the truth to both the patient and her relatives was always the most appropriate decision $(M=8.20)$, but their position was more nuanced than in the previous cluster. Hiding the truth from the patient but not from the relatives was not considered as fully inappropriate $(M=5.77)$. As in the previous cluster, however, hiding the truth from the patient's relatives was considered as inappropriate $(\mathrm{M}=2.09)$. This cluster was called "Tell the truth".

For 17 participants $(8 \%)$, telling the truth to both the patient and her relatives was not always the most appropriate decision. This cluster was called "Depends on situation", because when the patient was psychologically frail, or when she did not insist on knowing the full truth, minimizing the severity of the illness was considered as more appropriate. The Robustness x Decision interaction was significant. When the patient was psychologically robust, telling the full truth was considered as more appropriate $(\mathrm{M}=7.24)$ than the other options $(\mathrm{M}=$ 4.89 and 3.06, respectively). When the patient was psychologically frail, not telling the full truth 
was considered as more appropriate $(M=6.42)$ than the other options $(M=4.77$ and 4.30, respectively). The Physician's Behavior x Patient's Wishes interaction was also significant. When the patient wished to know the full truth, telling it was considered as more appropriate (M $=6.53)$ than the other options $(M=5.15$ and 3.56, respectively). When the patient did not insist on knowing the full truth, not telling it was considered as more appropriate $(M=6.16)$ than the other options ( $\mathrm{M}=5.48$ and 3.80, respectively). Overall, however, telling the full truth was considered as more appropriate $(M=6.01)$ than the other two options $(M=5.65$ and 3.68, respectively).

For 70 participants $(33 \%)$, hiding the truth from the patient, but telling the full truth to her relatives was, in most cases, considered as the most appropriate option $(\mathrm{M}=8.68)$. Telling the full truth to the patient was considered as less appropriate $(M=6.76)$, although hiding the truth was considered as clearly inappropriate $(\mathrm{M}=2.08)$. This cluster was called "Tell the truth to the Relatives". When the illness was lethal, any physician's decision was considered as less appropriate $(M=5.74)$ than when the illness was curable $(M=6.11)$. The Robustness $x$ Decision interaction was significant. When the patient was psychologically robust, telling the full truth was considered as more appropriate $(M=7.22)$ than when the patient was frail $(M=6.29)$. When the patient was psychologically frail, not telling the full truth was considered as more appropriate $(M=8.99)$ than in the other case $(M=8.37)$. The Social support $x$ Decision interaction was also significant. When the patient was not left alone, telling the full truth was considered as more appropriate $(\mathrm{M}=7.27)$ than when the patient was not frequently visited $(\mathrm{M}=$ 6.25). Lastly, the Severity x Decision interaction was significant. Telling the full truth was considered as more appropriate when the illness was not lethal $(M=7.55)$ than in the other cases $(\mathrm{M}=6.31$ and 6.41, respectively). 
Finally, for the remaining 89 participants (42\%), hiding the truth from the patient but telling the full truth to her relatives was in all cases considered as the most appropriate option $(M$ $=7.11$ ). Telling the full truth to the patient or hiding the truth from her family was considered as much less appropriate ( $M=3.51$ and 3.86, respectively). This cluster was called "Don't Tell the Truth to the Patient". When the illness was lethal, any physician's decision was considered as less appropriate $(M=4.70)$ than when the illness was curable $(M=5.09)$. The Robustness $\mathrm{x}$ Decision interaction was significant. When the patient was psychologically robust, telling the full truth was considered as more appropriate $(M=4.04)$ than when she was frail $(M=2.98)$. When the patient was psychologically frail, hiding the truth was considered as more appropriate $(M=$ 4.30) than when she was robust $(M=3.43)$. Lastly, the Severity $x$ Decision interaction was significant. Telling the full truth was considered as more appropriate when the illness was not lethal $(M=4.44)$ than in the other cases $(M=3.04$ and 3.05, respectively).

$\mathrm{Chi}^{2}$ statistics showed that the composition of the clusters differed significantly as a function of the participants' demographic characteristics. Older participants, males, and Muslims were more frequently found in the "Don't tell the truth" cluster than other groups.

\section{DISCUSSION}

The present study was the first on the African continent to inventory people's views regarding the breaking of bad news by a physician. The first hypothesis was that several qualitatively different positions would be found. Results supported this hypothesis: five positions were found. Among them, four were the same as those reported by Igier et al. (2015): “Always tell the full truth", "Tell the truth", "Depends on patient's wishes", and "Be gentle with patients". 
The second hypothesis was that the percentages of African participants holding each of these positions would be different from those observed in studies of European participants (Igier et al. 2015). The data supported this hypothesis. A relative majority of the participants (36\%) in the French study (Igier et al. 2015) considered that the full truth must be told directly to patients although they also understood that the physician might inform the family first. In contrast, such a position was held by only $15 \%$ of this study's participants. A more preferred position (33\%), similar to "Tell the truth", but in which the priorities were inverted, was to inform the family first. Also, among the French, the second most frequent position (28\%) was "Always tell the full truth to the patient". In contrast, such a position was held by less than $2 \%$ of the African participants. These findings are consistent with previous empirical studies in sub-Saharan African countries that suggested that respect for individual autonomy in health care is not a strongly endorsed value among African people (Kpanake, Dassa, Sorum, \& Mullet, 2014; Solum, Maluwa, \& Severinsson, 2012). Thus, while in the West any reluctance to tell bad news directly to patients is often blamed on physician paternalism (Beauchamp \& Childress, 2008; Jennings, 2014), in Africa it is more a result of people's widely-shared cultural beliefs (Harris, Shao, \& Sugarman, 2003; Solum, Maluwa, \& Severinsson, 2012). If the individual is not distinct from the family and the community, telling the family before, or rather than, the patient may not be seen as ethically problematic.

Among the French, the less frequent position (13\%) was "Be gentle with patients"; that is, don't inform them, especially if they are psychologically frail. In the present study, such a position was, in contrast, held by a relative majority (42\%), especially among older males and Muslims. This finding is consistent with the idea that the principle of non-malevolence is dominant among people in Togo. As stated earlier, many African people consider that discussing 
negative events may prompt their occurrence (Beyene, 1992; Harris, Shao, \& Sugarman, 2003).

Accordingly, withholding bad news from patients could protect them from harmful consequences and, in the case of medical bad news, could prevent or postpone fatal outcomes. In addition, contrary to the situation in Western Europe where all kinds of treatments are available, in Western Africa treatment options are, most of the time, limited. It is thus logical to view not undermining patients' hope as crucial, because maintaining hope is sometimes the only coping strategy available.

Finally, the position of systematically adjusting health communication to the many circumstances of the situation was endorsed by few African participants (only 8\%, compared to $23 \%$ in France). The strong belief that the patient must be protected at all costs does not leave much room for nuanced practices.

Overall: (a) an overwhelming majority of participants considered that the most appropriate strategy was not to inform the patient directly, but to inform the family first in all cases (75\%) or when the patient was psychologically frail (an additional 8\%); and (b) a notable proportion of participants (42\%) considered that directly informing the patient was even less appropriate than hiding the truth from everybody. These figures are in accordance with Blank's (2011, p. 204) suggestion that: "[t]hree-quarters of the world's population is not linked to concepts such as individual autonomy and truth-telling that are assumed by the conventional western bioethics community as critical in medicine" (see also, DelVecchio Good, Mwaikambo, Amayo, \& Machoki, 1999; Harris, Shao, \& Sugarman, 2003).

\section{Limitations}

The study had limitations. First, the group of participants was a convenience sample of lay people in one area of Togo; our findings must, therefore, be generalized with care and need 
to be replicated both in Togo and other African countries. Second, the participants responded to vignettes, not to real patients. Even though reading vignettes is different from being in the real health communication situation, vignettes are commonly used to study clinicians' and patients' opinions (e.g., Zwaanswijk et al., 2011), and their use has been validated (for a review, see Ulrich \& Ratcliff, 2008). Third, the patient in the vignette was always an elderly female who was cognitively intact. The potential impact of this patient's characteristics on the participants' responses - whether, in particular, they would endorse telling bad news to a man more than to a woman-is unknown. This seems likely, particularly, in African societies where men are considered to be stronger than women (Barker \& Ricardo, 2005). Therefore, future studies should explore the effect of patients' age, gender, cognitive state, and other personal characteristics on appropriateness judgments. Fourth, the experimenter did not ask further questions to elucidate the reasons behind the participants' responses; personal and cultural factors may be at play.

\section{Implications}

Consistent with suggestions from previous studies (Beyene, 1992; Harris, Shao, \& Sugarman, 2003; Solum, Maluwa, \& Severinsson, 2012), the main findings from this study present a challenge to European physicians working in either Europe with African patients or in African hospitals, and to African physicians trained in Europe and now working in their home countries. In Western medicine, physicians have been taught over the past half-century to abandon paternalism and respect the wishes of their patients (Fitts \& Ravdin 1953; Oken, 1961). On the one hand, therefore, they will be inclined to apply the autonomy principle of ethics in the communication of bad news, a principle that, in line with their training, they are likely to consider as the primary guide of their actions. This would allow them to honor the ethical 
imperative to tell the truth directly to their patients. On the other hand, they will realize that such a behavior may trigger anger and misunderstanding among their African patients, not to mention negative reactions from their patients' families.

As the present results indicate, however, patients differ in their ethical positions even in Africa. Some of our participants (17\%) held views similar to those of the majority in Europe. If physicians can detect this, they can apply a more Western conception of ethics and tell the full truth to the patient. In contrast, the vast majority of participants (75\%) felt that the best way to communicate bad news is to inform the family. Physicians are advised to understand that, in these cases, it is the role of the family - in particular, the elders - to break the news to the patient. In the African cultural context, it is their task, not the physician's, to decide on the appropriate time, place, and manner to deliver the bad news to their sick kinsman (Asante \& Mazama, 2008).

The physician will do well to realize that, in many cases, patients in Africa, more than in Western countries, do not want their autonomy to be respected, i.e. they do not want to hear a poor prognosis. This may be a moral problem for the physician, but not for the patient. Not only is the patient likely to agree that telling the family first is appropriate, but she or he may believe that talking about death, with the physician or others, will attract it and thereby make the situation worse. Forcing the delivery of truth on a patient who might not be psychologically ready to cope with its impact is insensitive, with the potential for additional harm as a result (Barclay, Blackhall, \& Tulsky, 2007; Pergert \& Lützén, 2012).

Thus, the cross-cultural consistency of individual variations in preferences for physicians' delivery of bad news strengthens the importance for physicians, at the time of delivering bad news, to tailor their interventions to each patient, in Africa as well as in the West, 
instead of using a "one size fits all" approach or an alternative "two sizes fit all, one for Africans and one for Europeans". Future studies in Africa should systematically examine individuals' personal wishes in order (a) to know whether people's opinions about breaking bad news to others are coherent with what individuals would prefer regarding themselves, and (b) to help devise a culturally acceptable way to ask individual patients about their preferences. 


\section{References}

Anderson, N. H. (2008). Unified social cognition. New York: Psychology Press.

Asante, M. K. \& Mazama, A. (2008). Encyclopedia of African religion. Thousand Oaks, CA: Sage Publications.

Barclay, J. S., Blackhall, L. J., \& Tulsky, J. (2007). Communication strategies and cultural issues in the delivery of bad news. Journal of Palliative Medicine, 10, 958-977.

Barker, G., \& Ricardo, C. (2005). Young men and the construction of masculinity in sub-Saharan Africa: Implications for HIV/AIDS, conflict, and violence. Social Development Paper $\mathrm{N}^{\circ}$ 26. Conflict Prevention \& Development, The World Bank: Washington.

Barnett, M. M., Fisher, J. D., Cooke, H., James, P. R., \& Dale, J. (2007). Breaking bad news: Consultants' experience, previous education and views on educational format and timing. Medical Education, 41, 947-956.

Beauchamp, T. L., \& Childress, J. F. (2008). Principles of biomedical ethics (6 ${ }^{\text {th }}$ ed.). New York, NY: Oxford University Press.

Beyene, Y. (1992). Medical disclosure and refugees: Telling bad news to Ethiopian patients. Western Journal of Medicine, 157, 328-332.

Blank, R. H. (2011). End-of-life decision making across cultures. Journal of Law, Medicine \& Ethics, 39, 201-214.

Blier, S. P. (1996). African vodun: Art, psychology, and power. Chicago and London: University of Chicago Press.

Brown, L. M. (2004). African philosophy: New and traditional perspectives. New York: Oxford University Press. 
DelVecchio Good, M. J., Mwaikambo, E., Amayo, E., \& Machoki, J. M. (1999). Clinical realities and moral dilemmas: Contrasting perspectives from academic medicine in Kenya, Tanzania, and America. Daedalus, 128, 167-196.

Fields, S. A., \& Johnson, W. M. (2012). Physician-patient communication: Breaking bad news. West Virginia Medical Journal, 108, 32-35.

Fitts, W. T., Jr., \& Ravdin I. S. (1953). What Philadelphia physicians tell patients with cancer? Journal of the American Medical Association, 153, 901-904.

Fox, R. C. (1990). The evolution of American bioethics: A sociological perspective. In G. Weisz (Ed.), Social sciences perspectives on medical ethics (pp. 201-217). Dordrecht: Kluwer Academics Publishers.

Franks, P., Fiscella, K., Shields, C. G., Meldrum, S. C., Duberstein, P., Jerant, A. F., ...Epstein, R. M. (2005). Are patients' ratings of their physicians related to health outcomes? Annals of Family Medicine, 3, 229-234.

Hallen, B. (2009). A short history of African philosophy. Bloomington: Indiana University Press. Hagerty, R. G., Butow, P. N., Ellis, P. M., Lobb, E. A., Pendlebury, S. C., Leighl N., ...Tattersall, M. H. N. (2005). Communicating with realism and hope: Incurable cancer patients'views on the disclosure of prognosis. Journal of Clinical Oncology, 23, 12781288.

Harris, J. J., Shao, J., \& Sugarman, J. (2003). Disclosure of cancer diagnosis and prognosis in Northern Tanzania. Social Science \& Medicine, 56, 905-913.

Hofmans, J., \& Mullet, E. (2013). Towards unveiling individual differences in differences in different stages of information processing: A clustering-based approach. Quality \& Quantity, 47, 455-464. 
Igier, V., Muñoz Sastre, M-T., Sorum, P. C., \& Mullet, E. (2015). A mapping of people's positions regarding the breaking of bad news to patients. Health Communication, 30, 694-701.

Jennings B. (Ed.) (2014). Encyclopedia of bioethics, $4^{\text {th }}$ Edition, New York: MacMillan Publishing Company.

Kaplan, M. (2010). SPIKES: A framework for breaking bad news to patients with cancer. Clinical Journal of Oncology Nursing, 14, 514-516.

Kleinman, A. (1999). Moral experience and ethical reflection: Can ethnography reconcile them? A quandary for "the new bioethics". Daedalus, 128, 69-97.

Kpanake, L., Dassa, S. K., Sorum, P. C., \& Mullet, E. (2014). Togolese lay people's and health professionals' views about the acceptability of physician-assisted suicide. Journal of Medical Ethics, 40, 621-624.

Levinson, W., Lesser, C. S., \& Epstein, R. M. (2010). Developing physician communication skills for patient-centered care. Health Affairs, 29, 1310-1318.

Levinson, W., Roter, D. L., Mullooly, J. P., Dull, V. T., \& Frankel, R. M. (1997). Physicianpatient communication: The relationship with malpractice claims among primary care physicians and surgeons. Journal of the American Medical Association, 277, 553-559.

Miyata, H., Takahashi, M., Saito, T., Tachimori, H., \& Kai, I. (2005). Disclosure preferences regarding cancer diagnosis and prognosis: To tell or not to tell? Journal of Medical Ethics, 31, 447-451.

Oken, D. (1961). What to tell cancer patients: A study of medical attitudes. Journal of the American Medical Association, 175, 1120-1128. 
Öksüzoğlu, B., Abalı, H., Bakar, M. Yıldırım, \& Zengin N. (2006). Disclosure of cancer diagnosis to patients and their relatives in Turkey: Views of accompanying persons and influential factors in reaching those views. Tumori, 92, 62-66.

Pauls, M.A., \& Ackroyd-Stolarz, S. (2006). Identifying bioethics learning needs: A survey of Canadian emergency medicine residents. Academic Emergency Medicine, 13, 645-652.

Pergert, P., \& Lützén, K. (2012). Balancing truth-telling in the preservation of hope: A relational ethics approach. Nursing Ethics, 19, 21-29.

Selman, L., Higginson, I. J., Agupio, G., Dinat, N., Downing, J., Gwyther, L., .. Harding, R. (2009). Meeting information needs of patients with incurable progressive disease and their families in South Africa and Uganda: Multicentre qualitative study. British Medical Journal, 338, b1326.

Shofield, P. E., Butow, P. N., Thompson, J. F., Tattersall, M. H., Beeney, L. J., \& Dunn, S. M. (2003). Psychological responses of patients receiving the diagnosis of cancer. Annals of Oncology, 14, 48-56.

Silbermann, M. \& Hassan, E. A. (2011). Cultural perspectives in cancer care: Impact of Islamic traditions and practices in Middle Eastern countries. Journal of Pediatric Hematology/Oncology, 33, S81-S86.

Sise, M. J., Sise, C. B., Sack, D. I., \& Goerhing, M. (2006). Surgeons' attitudes about communicating with patients and their families. Current Surgery, 63, 213-218.

Solum, E. M., Maluwa, V. M., \& Severinsson, E. (2012). Ethical problems in practice as experienced by Malawian student nurses. Nursing Ethics, 19, 128-138. 
Ulrich, C. M., \& Ratcliffe, S. J. (2008). Hypothetical vignettes in empirical bioethics research. In L. Jacoby, \& L. A. Siminoff (Eds.), Empirical methods for bioethics: A primer (pp. 161182). Oxford, UK: Elsevier JAI Press.

United Nations, Department of Economic and Social Affairs, Population Division (2013). World Mortality Report 2013. United Nations publication.

Watermeyer, J. \& Penn, C. (2012). “Only two months destroys everything”: A case study of communication about nonadherence to antiretroviral therapy in a South African HIV pharmacy context. Health Communication, 27, 602-611.

Wuensch, A., Tang, L., Goelz, T., Zhang, Y., Stubenrauch, S., Song, L., ... Fritzsche, K. (2013). Breaking bad news in China: The dilemma of patients' autonomy and traditional norms. A first communication skills training for Chinese oncologists and caretakers. PsychoOncology, 22, 1192-1195.

Zwaanswijk M., Tates, K., van Dulmen, S., Hoogerbrugge, P. M., Kamps, W A., Beishuizen, A., \& Bensing, J. M. (2011). Communicating with child patients in pediatric oncology consultations: A vignette study on child patients', parents', and survivors' communication preferences. Psycho-Oncology, 20, 269-277. 
Table 1. Demographic Characteristics of the Clusters

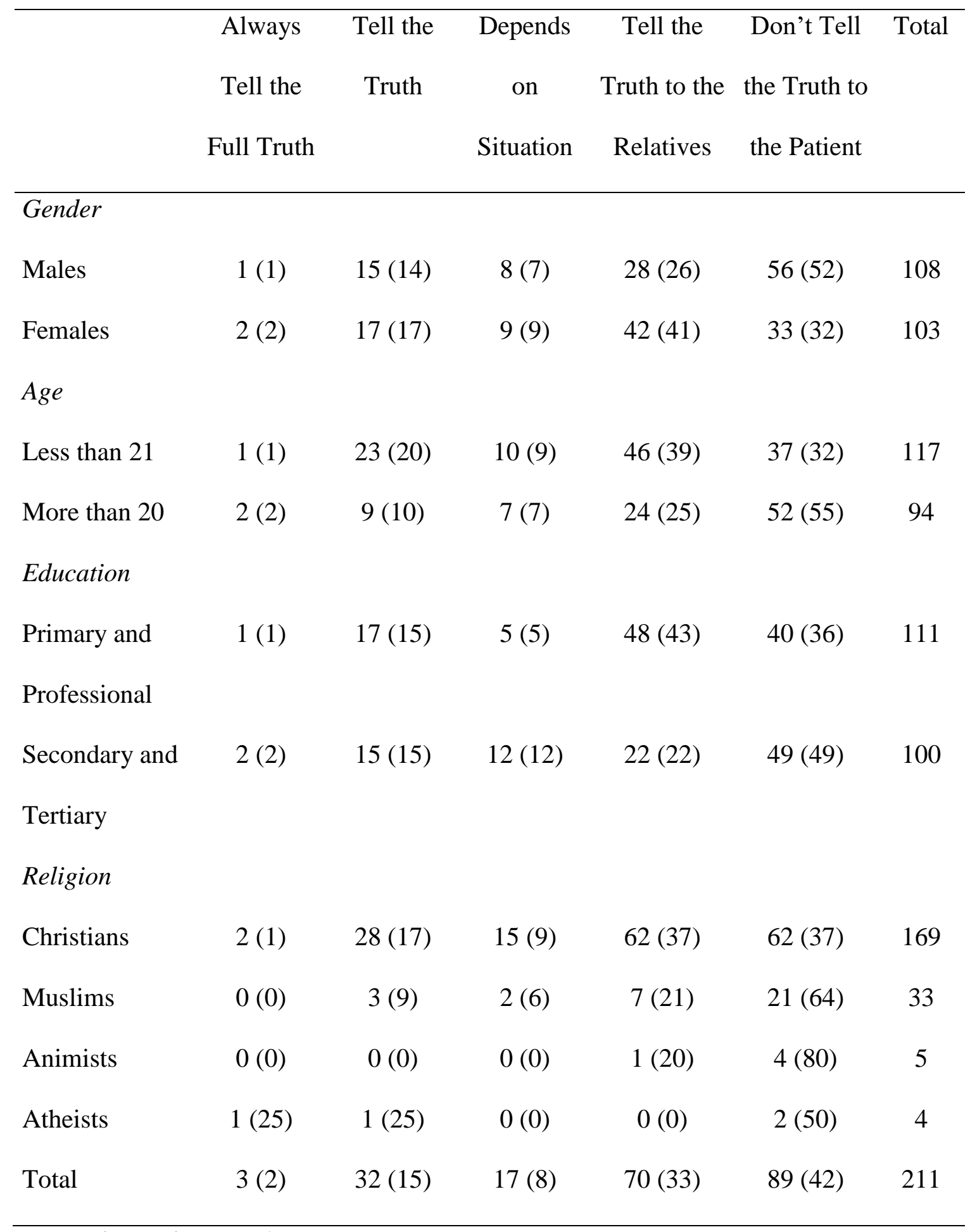

Note: Figures in parentheses are percentages. 
Table 2. Main Results of the ANOVAs Performed on Four of the Five Clusters

\begin{tabular}{|c|c|c|c|c|c|}
\hline & $d f$ & $M S$ & $F$ & $p$ & $E t a_{p}^{2}$ \\
\hline \multicolumn{6}{|l|}{ Cluster Tell the Truth } \\
\hline Psychological Robustness (R) & 1 & 35.38 & 8.82 & .01 & .23 \\
\hline Social Support (S) & 1 & 9.95 & 1.42 & .24 & .05 \\
\hline Patient's Wishes (W) & 1 & 0.91 & 0.15 & .70 & .00 \\
\hline Severity of the Illness (I) & 2 & 1.07 & 0.24 & .79 & .01 \\
\hline Physician's Decision (D) & 2 & 7047.25 & 353.48 & .001 & .92 \\
\hline \multicolumn{6}{|l|}{ Cluster Depends on the Situation } \\
\hline Psychological Robustness (R) & 1 & 3.04 & 0.48 & .49 & .03 \\
\hline Social Support (S) & 1 & 26.77 & 2.29 & .14 & .12 \\
\hline Patient's Wishes (W) & 1 & 1.37 & 0.61 & .44 & .04 \\
\hline Severity of the Illness (I) & 2 & 13.39 & 1.88 & .16 & .10 \\
\hline Physician's Decision (D) & 2 & 639.65 & 50.26 & .001 & .76 \\
\hline $\mathrm{R} \times \mathrm{D}$ & 2 & 505.51 & 16.13 & .001 & .50 \\
\hline W x D & 2 & 111.42 & 12.62 & .001 & .44 \\
\hline \multicolumn{6}{|c|}{ Cluster Tell the Truth to the Relatives } \\
\hline Psychological Robustness (R) & 1 & 0.12 & 0.01 & .90 & .00 \\
\hline Social Support (S) & 1 & 66.32 & 5.74 & .02 & .08 \\
\hline Patient's Wishes (W) & 1 & 23.27 & 3.92 & .05 & .05 \\
\hline Severity of the Illness (I) & 2 & 94.93 & 11.53 & .001 & .14 \\
\hline Physician's Decision (D) & 2 & 19071.09 & 536.62 & .001 & .89 \\
\hline
\end{tabular}




\begin{tabular}{|c|c|c|c|c|c|}
\hline \multirow{2}{*}{ R x D } & & & & \multicolumn{2}{|c|}{ Breaking bad news } \\
\hline & 2 & 283.39 & 15.31 & .001 & .18 \\
\hline$S \times D$ & 2 & 245.47 & 20.85 & .001 & .23 \\
\hline I x D & 4 & 95.34 & 9.41 & .001 & .12 \\
\hline \multicolumn{6}{|l|}{ Cluster Don't Tell the Full Truth } \\
\hline Psychological Robustness (R) & 1 & 8.40 & 1.03 & .31 & .01 \\
\hline Social Support (S) & 1 & 6.12 & 1.03 & .31 & .01 \\
\hline Patient's Wishes (W) & 1 & 6.37 & 1.12 & .29 & .01 \\
\hline Severity of the Illness (I) & 2 & 108.68 & 13.31 & .001 & .13 \\
\hline Physician's Decision (D) & 2 & 8419.55 & 106.07 & .001 & .55 \\
\hline$R \times D$ & 2 & 501.54 & 23.42 & .001 & .21 \\
\hline $\mathrm{I} \times \mathrm{D}$ & 4 & 191.80 & 20.19 & .001 & .19 \\
\hline
\end{tabular}




\section{Figure caption}

Figure 1: Patterns of results corresponding to the five clusters: Always the full truth, Tell the truth in most cases, Depends on the situation, Tell the truth to the relatives, and Don't tell the truth to the patient. In each panel, (a) the judged appropriateness of the physician's behavior is on the $y$-axis (b) the three levels of the physician's behavior are on x-axis, and (c) the two curves correspond to the two levels of the patient's psychological robustness. 
Breaking bad news
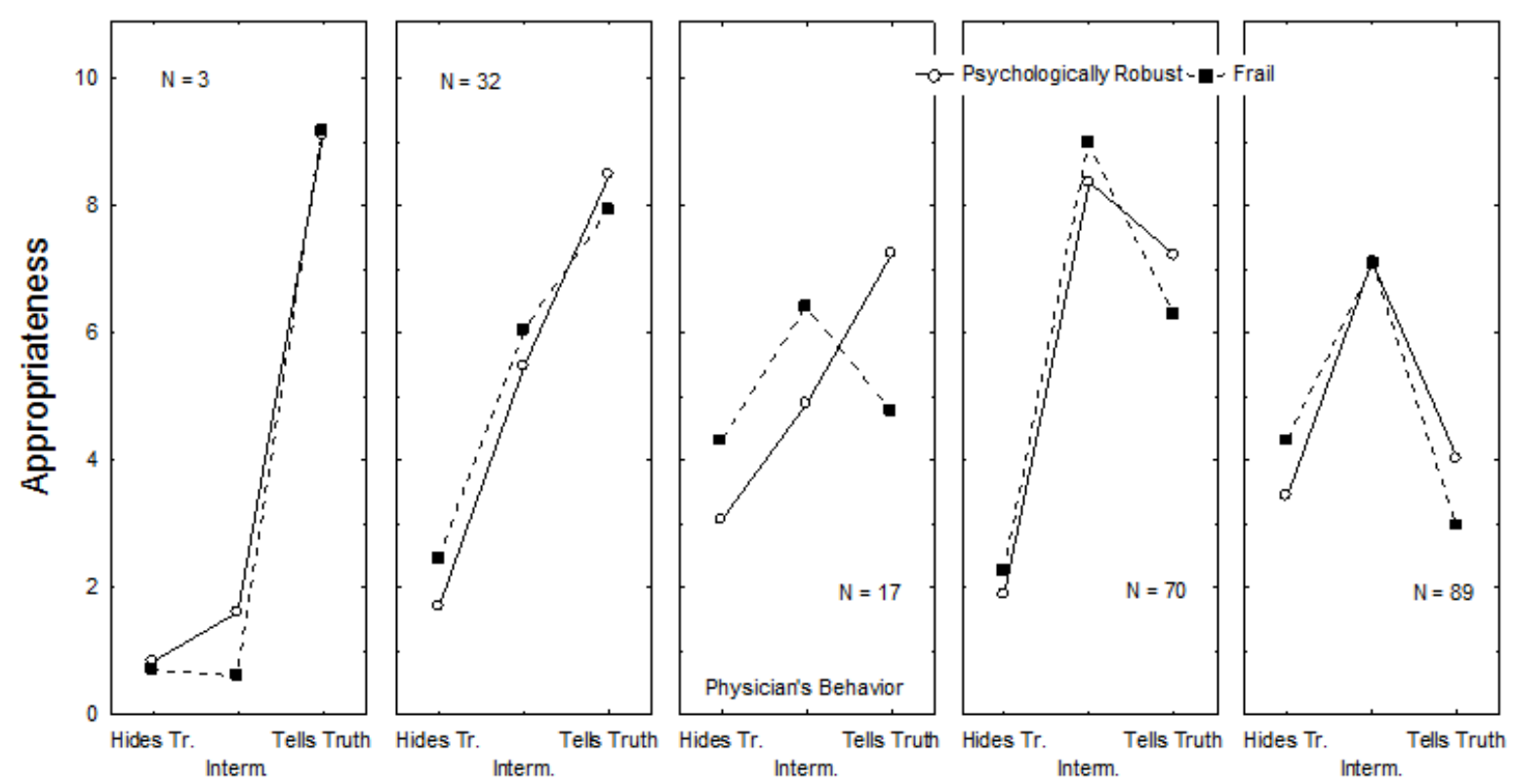

Always Full Truth

Tell the Truth

Dep. on Situation

Truth to Relatives

Don't Tell to Patient 